\title{
La identidad profesional de los trabajadores sociales como elemento clave en el acceso a los programas de rentas mínimas: el caso de Catalunya
}

\author{
Joan Cortinas Muñoz \\ Centre de Recherches Sociologiques et Politiques de Paris \\ <joan.cortinas@csu.cnrs.fr>
}

Bertan azaldutako lanak ezagutu nahi ditu arlo sozialeko profesionalek eguneroko praktikan erabiltzen dituzten arauak. Izan ere, arauen ezagutza horren arabera, herritarrak ezegonkortasunaren kontrako baliabide publikoetara iristeko txostena egin edo ez erabakiko baita. Horretarako, kontuan hartzen da Kataluniako sailen arteko oinarrizko errentaren programako (PIRMI) kasuen azterketa. Bertan defendatutako tesiaren arabera, arau horiek oinarritzen dira nortasun profesional batean, aztertutako gizarte-langintzako profesionalek bereberea duten hezkuntzaren alorreko langintzan. Ikuspegi honetatik, -oinarrizko errentaaitortzeko agirien tramitazioa egitean, hein handi batean behintzat, gizarte-langileak ulertuko du hezkuntzaren alorreko betekizuna egiten duela, eta, azken batean, baliodunduko du bere nortasun profesionala.

\section{HITZ-GAKOAK:}

oinarrizko errenta, gizarte-laguntza, Katalunia, ezegonkortasuna, pobrezia.
El trabajo que aquí presentamos quiere explorar las normas que usan los profesionales de lo social en su práctica cotidiana para proceder o no a la tramitación del informe que puede dar acceso a un ciudadano a los dispositivos públicos que intentan luchar contra la precariedad. Para ello, nos centramos en el estudio de caso de los procesos de acceso al Programa Interdepartamental de la Renta Mínima de Inserción (PIRMI) en Catalunya. La tesis defendida es que esas normas se apoyan en una identidad profesional basada en el concepto de trabajo 'educativo' propia a los profesionales del trabajo social analizados. Desde este punto de vista, la tramitación de los documentos que dan acceso al derecho -la renta mínima de inserción- será sometida, en parte, al hecho que el trabajador social considere que dicho acceso le permitirá desarrollar una tarea 'educativa', o lo que es lo mismo, validar su identidad profesional.

\section{Palabras clave:}

renta mínima, trabajo social, Catalunya, precariedad, pobreza. 


\section{Introducción}

A partir de finales de los años ochenta, los diferentes Gobiernos autonómicos del Estado español ponen en marcha los dispositivos conocidos como políticas de rentas mínimas (Aguilar et al., 1995; Arriba, 1999). Estos dispositivos se caracterizan, entre otras cuestiones, por el hecho de establecer una magistratura de lo social en el acceso al derecho (Castel, 1995: 763). Es decir, los criterios de los profesionales de lo social -trabajadores sociales y educadores- tienen un peso en los procesos de acceso o en el disfrute del derecho.

En este artículo nos interesaremos en el contenido de dicha magistratura de los profesionales de lo social. Para ello, nos centramos en el estudio del programa de renta mínima en Catalunya: el Programa Interdepartamental de la Renta Mínima de Inserción (PIRMI) [Generalitat de Catalunya, 1990, 1997, 1998, 2001a y $2001 b]$. Nuestra tesis será que uno de los elementos que estructura la magistratura ${ }^{1}$ ejercida por los trabajadores de los servicios sociales estudiados está relacionado con la identidad profesional de éstos. Más concretamente, la decisión de tramitar el acceso al PIRMI no suscita ninguna duda al trabajador social cuando dicha tramitación valida su identidad profesional: desarrollar un trabajo ‘educativo'. Y a la inversa, la tramitación se torna más tortuosa y peor vivida por parte del trabajador social cuando sus motivos no refuerzan dicha identidad profesional. Defenderemos también que dicha identidad profesional está fuertemente vinculada a las trayectorias sociales de las personas entrevistadas.

Para exponer dicha tesis describiremos, en un primer momento, la posición que ocupan los trabajadores sociales de los servicios sociales de base ${ }^{2}$ en la arquitectura del PIRMI. En segundo lugar, nos centraremos en presentar la estructura de la identidad profesional de dichos trabajadores sociales, y terminaremos dando algunos ejemplos en los que dicha relación entre identidad profesional y magistratura de lo social se materializa.

Este artículo se basa en un estudio etnográfico llevado a cabo en los servicios sociales de dos grandes ciudades catalanas, y que se inscribe en los trabajos sociológicos basados en el estudio etnográfico de la política pública en sus materializaciones locales (Dubois, 2003a y 2003b; Lipsky, 1980; Tissot,

${ }^{1}$ Para conocer la totalidad de elementos que dan contenido, en el caso catalán, a la noción de magistratura de lo social, véase Cortinas (2010).

${ }^{2}$ Los servicios sociales de base son la puerta entrada al sistema de servicios sociales en Catalunya. Estos servicios son de carácter municipal y se sitúan en el territorio a partir de una lógica de proximidad con los ciudadanos. Se accede a estos servicios pidiendo una simple cita por teléfono, o presencialmente en una de las oficinas existentes. Estos servicios reciben a los ciudadanos y tienen la potestad de tramitar el informe que materializa la demanda de acceso al PIRMI. Son los profesionales de estos servicios los que están encargados del seguimiento de los usuarios una vez que han accedido al PIRMI. En este rol de seguimiento, pueden proceder a pedir la suspensión temporal o permanente de un usuario en el PIRMI.
2007). El estudio ha consistido en una observación no participante en una oficina de servicios sociales durante cuatro meses, durante los cuales asistimos a las entrevistas que los profesionales tienen con los usuarios del PIRMI y con usuarios que aún no gozan de dicha prestación. Igualmente, hemos realizado 21 entrevistas con educadores y trabajadores sociales ${ }^{3}$ acerca de sus maneras de concebir la renta mínima y el uso que hacen de dicha prestación: cuándo la consideran importante, cuándo deciden evitar la tramitación, cuándo deciden suspender la prestación, entre otras cuestiones. La segunda ciudad ha servido de dispositivo de control respecto a los resultados obtenidos en la primera. El estudio fue realizado entre 2006 y 2009.

\section{Los trabajadores sociales como actores centrales en los procesos de tramitación y suspensión de demandas de acceso al PIRMI}

Los trabajadores sociales de los servicios sociales de base manifiestan tener una gran facilidad, o dicho de otra manera, no tener ningún tipo de restricción remarcable o directiva a la hora de tramitar o gestionar la renta mínima de inserción. Al contrario, la mayoría de ellos parecen no tener ningún problema en que las demandas que tramitan gocen de un alto porcentaje de aprobación por el órgano técnico del PIRMI. Este órgano, compuesto esencialmente por trabajadores sociales y dirigido por un educador Francesc Coll- goza, a su vez, de una gran autonomía en dichas aprobaciones. Así, el hecho de que no se apruebe una demanda de acceso al PIRMI realizada por un trabajador social es vivida como una sorpresa y una rareza4.

De la misma manera, la suspensión de un expediente propuesta por un trabajador social difícilmente encuentra obstáculos por parte del organismo de gestión del PIRMI, e incluso algún trabajador social nos cuenta que el órgano técnico del PIRMI -que proporciona soporte a la gestión y decisión del principal órgano responsable del PIRMI, la Comisión Interdepartamental de la Renta Mínima de Inserción-, cuenta con un técnico de referencia a cada equipo de los servicios sociales de base, con el que se puede establecer fácilmente contacto telefónico para arreglar cuestiones relativas a los expedientes. Estas decisiones se toman de forma individual y se someten a una supervisión que actúa más como soporte de dicha decisión que como evaluadora, y hacen que podamos hablar de un dispositivo en el que el acceso y la permanencia están, en buena parte, en manos del trabajador social de los servicios sociales.

${ }^{3}$ A las personas entrevistadas se las identificará en este artículo mediante sus iniciales y año de nacimiento. El entrevistador aparece indicado como 'Ego'.

${ }^{4}$ Los datos oficiales facilitados por el órgano técnico del PIRMI sitúan las demandas denegadas alrededor del $20 \%$ entre 2005 y 2009 (en concreto, $20,6 \%$ en $2005,20,8 \%$ en $2006,20,6 \%$ en $2007,21,3 \%$ en 2008 , y $20,6 \%$ en 2009), años de realización de nuestro trabajo de campo. 
En varias ocasiones los trabajadores sociales entrevistados hablan de los procesos de concesión o suspensión de la renta mínima de inserción en primera persona. Así, una trabajadora nos cuenta:

-D. A.: Tenía a unos a quienes se la cerré, y se generó un pitote. La cerré yo, aunque la demanda era la de la trabajadora social, porque el tío llevaba 10012 años en motivación, y el tío se lo había tomado como una pensión [...]. Ahora, el hijo ha venido y me ha pedido la PIRMI [...].

(D. A., 1976, educador social, dos años en los servicios sociales de base) [subrayado del autor].

Vemos cómo el educador social se pone como sujeto de la suspensión, "la cerré”, reforzando así la idea de que los profesionales de atención primaria gozan de una autonomía en la decisión que parece no estar sometida a directivas políticas, ni al control de sus superiores, y que trasladan estas decisiones al terreno puramente profesional, en el marco de una relación interpersonal entre el profesional y el 'usuario'.

Esta característica del PIRMI lo distingue de otros dispositivos, como los procesos de gestión de las demandas de permisos de residencia o de asilo político, en los que las directivas políticas parecen influir directamente, mediante fuertes controles y sanciones, en las lógicas de gestión de los agentes del Estado que las ejecutan, y donde se trata, ante todo, de actuar en función de las directivas políticoadministrativas, es decir, de ejecutar una tarea de aplicación de las normas (Spire, 2008). Este ausencia de conexión entre directivas políticas y proceso localizado de decisión, seguimiento y evaluación de la renta mínima de inserción da al trabajador social un margen de libertad respecto a coyunturas políticas, pero no lo libra, sin embargo, del hecho de que el PIRMI es un dispositivo extremamente burocratizado y jerarquizado en su funcionamiento, en el que el trabajador social de los servicios sociales de base ocupa una posición subordinada en lo que concierne las decisiones respecto a los recursos existentes para la ‘inserción' -naturaleza y cantidad-y sus temporalidades -inicio y duración de las actividades-.

\section{Una identidad profesional estructurada alrededor de la noción de trabajo 'educativo'}

Los profesionales que componen nuestro universo de estudio se asemejan, por toda una serie de elementos que vamos a ir desgranando en las próximas líneas, a un segmento de lo que Bourdieu (1979) llama la pequeña burguesía. A grandes rasgos, sus trayectorias sociales están definidas por procesos de ascenso social desde unos orígenes populares o medios (Serre, 2009). Este ascenso tiene como base la escolaridad, pero la fragilidad de capitales iniciales les impide acceder a posiciones dominantes del espacio social y les conduce a una lógica de distinción respecto a estas posiciones. Es decir, se adhieren a la institución escolar y su valor como medio de ascenso social, pero buscan una profesión que sea accesible -por voluntad o falta de alternativas-, a partir de la cual se teje una posición social basada en recompensas simbólicas que provienen de la producción de valores distintivos de las clases dominantes y de las populares de las que son originarias: 'hacer tareas que sean enriquecedoras personalmente', 'que aporten cambios'. En resumen, 'tareas con sentido'.

De los 21 profesionales que componen nuestro universo de estudio, nos encontramos con una mayoría de diplomados en Trabajo Social. Así, 11 de los 21 son trabajadores sociales, mientras que 7 son diplomados en Educación Social, dos personas tienen como título académico principal la licenciatura de Psicología, y una, la de Magisterio.

El primer elemento que caracteriza a estos profesionales es la mayoritaria presencia de individuos de origen social que podríamos calificar de clase popular, si nos atenemos a la profesión de los padres y a los lugares de residencia. Así, de los 21 individuos, 15 (el 71\%) proceden de familias de padres obreros y sólo 6 (29\%) son pequeños empresarios o empleados calificados. Además, dentro de estos pequeños empresarios, dos poseen comercios en barrios populares. El resultado es que el lugar de residencia originario de 17 de nuestros 21 individuos son barrios populares de grandes ciudades. Por otro lado, en ninguno de los casos los progenitores poseen estudios superiores.

Estos orígenes populares se combinan, en la mayor parte de los casos, excepto uno, con una importante atribución de valor a los estudios de los hijos, que se traduce de distintas maneras, según los casos. Por ejemplo, toma la forma de una estrategia en la elección de escuelas:

-Ego: 0 sea, que te llevaron a una escuela del centro de la ciudad, y no del barrio.

-S. M.: Eso. Fíjate, mi madre quería llevarme a una escuela de fuera del barrio. Ellos eran andaluces, y mi madre decía: "Claro, si la llevo a una escuela del barrio, no hablará catalán; si la llevo al centro, le enseñarán a hablarlo”. ¡Uy! Y está muy orgullosa de haberlo hecho así [risas], por eso, por eso me llevaron a la escuela del centro.

(S. M., 1972, trabajadora social, un año en los servicios sociales de base).

-A: En La Salut, en un [colegio] concertado. Pues imagínate, mi padre no estaba de acuerdo que fuera concertado.

-Ego.: ¿Y por qué fue concertado?

-A.: Porque mi madre dijo ‘aquí mando yo’; es la escuela más cercana que tenemos, y porque en 
esa época la escuela pública no estaba como tan bien vista, y mi madre, como quería que estudiáramos aquí, mi madre dijo a mi padre que era un colegio de monjas.

(A., 1972, educadora social, ocho años en los servicios sociales de base).

En otros casos, se produce una participación activa de los padres en las asociaciones de padres de la escuela y, en la mayoría de casos, en un apoyo y una preocupación por la carrera escolar del hijo o la hija, materializada en conversaciones entre los padres e hijos sobre las decisiones escolares:

-Ego: ¿Tus padres daban importancia al hecho [de] que estudiases?

-A. N.: Sí, ¡mucho! Hasta que le dije a mi madre lo que iba a estudiar y me dijo que estaba medio loca, que ¡qué era eso que iba a estudiar!

-Ego.: 0 sea, [que] valoraban mucho los estudios hasta que entraste en Trabajo Social.

-A. N.: ¡Claro! “¿Qué es eso? ¿Por qué no haces Magisterio? ¿O Administración, y trabajas con tu tío, en el banco?".

(A. N., 1963, 23 años en los servicios sociales de base).

Esta inversión familiar en los estudios parece traducirse en escolaridades continuadas hasta el acceso a la Universidad. Es decir, todos los profesionales que forman parte de nuestro universo, excepto dos casos que ahora abordaremos, llegan a los cursos de acceso a la Universidad sin ninguna interrupción en dicha escolaridad. Los estudios primarios se encadenan con los secundarios con toda naturalidad. Sólo dos casos parecen salirse de esta norma, ya que interrumpen sus estudios secundarios a la mitad para ponerse a trabajar. Sin embargo, esta interrupción quedará en una anécdota, ya que años más tarde retomarán los estudios -las dos excepciones forman parte de las generaciones (1950 y 1960) en las que la entrada al mercado laboral sin calificación se produce de manera bastante cómoda-. A pesar de esa continuidad en los procesos de escolarización, sólo una minoría accede a los estudios de Educación Social o Trabajo Social como primera opción después de la Selectividad (4 de 21).

En otras palabras, la entrada a Educación Social o Trabajo Social es, para 17 de 21 (el 71\%), una oportunidad por defecto - nota baja que determina la elección o el acceso después de ser descartados en otros estudios- de acceso a los estudios universitarios, o una oportunidad de consolidar una experiencia profesional que demanda un título para conseguir una posición profesional más estable. En el primer caso, esta oportunidad por defecto -y vivida como un tanto casual- puede ser vivida como una manera de ver realizado el deseo de ejercer una profesión dedicada a 'los otros'. Es el caso de las tres mujeres que querían, o pensaron dedicarse a, profesiones del campo sanitario, pero que no consiguieron entrar en dichos estudios. El trabajo social parece cumplir esa función de estar en contacto con 'lo humano’:

-M. C.: Lo mío es un poco película. Yo hacía ciencias puras, pero tuve la mala suerte [de] que, en el instituto, me quedó una asignatura pa' septiembre, y tuve que hacer la Selectividad en septiembre. Iba para enfermera, no tenía en la familia nadie que me pudiera asesorar, era la primera que tenía estudios; en la familia paterna había gente, pero alrededor mío no tenía nadie que me pudiera asesorar. Entonces tuve la mala suerte [de] que no pude entrar en la Universidad. Entonces alguien me orientó hacia Trabajo Social; como era una de las carreras que quedaba, pues...; pero claro, para mí era algo nuevo. Entonces, en aquella época, hacía poco que era carrera universitaria, pero claro, lo que yo estudié no tiene nada que ver con lo que te encuentras en la realidad, pero fue un poco... interesante. ¡Hay que ver! Estuve a punto de dejarlo, pero como iba bien y sacaba buenas notas, pues...

-Ego: ¿Algo positivo de la profesión?

-M. C.: Bueno, positivo, hombre, hay cosas positivas, cuando veías que antiguamente podías informar de cosas. Lo mejor, cuando has visto familias que han cambiado, de ser ellos los que pedían y que, en un momento, se vuelven autónomos; o cuando la gente te viene a ver y te dan las gracias, porque les has informado muy bien, aunque no les des nada; o sea, la parte más humana. Aquí es lo que falta: la parte humana no existe, vienen a quejarse, enfadarse, pero nunca a darte las gracias; a nivel humano no hay ninguna valoración.

(M. C., 1967, trabajadora social, veinte años en los servicios sociales de base).

0:

-Ego: ¿Y terminaste en Trabajo Social?

-V. R.: No, yo no quería, yo quería ser odontóloga. Hice el bachillerato de ciencias de la salud.

-Ego.: ¿No te llegó la nota?

-V. R.: No me llegó la nota. La otra opción era Enfermería, pero tampoco me llegó, y me llegó para Trabajo Social [...], pero estoy muy contenta.

-Ego.: ¿Alguien te aconsejó o elegiste sola?

-V. R: Totalmente por azar, pero sí que, emmm..., [entre] las personas que nos dedicamos al mundo de lo social, sí que hay una serie de aptitudes. Cuando tú decides qué tipo de estudios, qué profesión quieres, pues ya sabes si van enfocados 
más a la ayuda a las personas, o algo más técnico, y entrarían las profesiones que están relacionadas.

(V. R., 1980, trabajadora social, cuatro años en los servicios sociales de base).

En otros casos, la falta de nota vinculada a escolarizaciones continuas, pero sin elevadas calificaciones, se combina con socializaciones en el mundo de lo social -asociaciones de ayuda a drogodependientes- o 'lo educativo’ -socialización en los esplais ${ }^{5}$ católicos o laicos, monitores de niños en dichos esplais-, que lleva a considerar los estudios de Trabajo Social o Educación Social:

-S. F.: Primero me interesaba[n] Periodismo y Derecho, y me fui a informar al Salón de la Enseñanza, y me cayó en las manos la información de Educación Social, y cuando vi el contenido, me pareció muy atractivo [...] como formación personal.

-Ego.: O sea, que fuiste por otras cosas y te encontraste con Educación Social

-S. F.: Sí, lo que tenía en mente era Derecho y Periodismo, que también tenían bastante vertiente social [...]. El tema social me llamaba mucho la atención [...].

(S. F., 1976, educador social, cinco años en los servicios sociales de base).

-T. T.: Hice bachillerato y empecé los estudios de Historia, que Historia no...

-Ego.: ¿Hiciste toda la carrera?

-T. T.: ¡No! Ya me hubiese gustado, pero era demasiado para mí.

-Ego.: ¿Por razones económicas?

-T. T.: Yo siempre he trabajado; además, mi memoria es bastante... Ya lo dice mi padre, que para hacer Historia hay que tener mucha memoria, y realmente no iba muy bien, no aprobaba, por mucho que me pusiera. Entonces decidí -porque mi idea era hacer Antropología, que me hubiera gustado-, pero al final fui realista, dejé Historia y empecé Educación Social.

Ego.: Pero tu deseo era Antropología, ¿por qué lo dejaste correr?

-T. T.: Porque yo hacía Historia para poder entrar en Antropología, y como no pude hacer Historia, no podía hacer Antropología, y como tenía mucha experiencia, e incluso había trabajado a nivel de chavales en exclusión social, no en esplais, pero había trabajado en este tema, entonces me dije:

${ }^{5}$ Los esplais son asociaciones que realizan actividades de ocio para niños y jóvenes orientadas a la educación en valores.
"Pues que para algo me sirva”, ¿no? Además, yo había estado en un centro abierto dos años con chavales [...].

(T. T., 1974, educadora social, dos años en los servicios sociales de base).

En continuidad con esta lógica que acabamos de describir, encontramos a individuos (5 de 21) en los que una oportunidad laboral real en el mundo de 'lo educativo' o 'lo social' les lleva a la facultad de Trabajo o Educación Social. De nuevo, en estos casos existe una socialización en 'lo educativo’ o, marginalmente, en 'lo político':

-D. A.: Hice BUP y COU en un instituto público de Santa Coloma, empecé Psicología por la UNED [Universidad Nacional de Educación a Distancia], lo dejé al cabo de tres años, porque hice la PSS [Prestación Social Substitutoria] en un centro de acogida, vi el mundo de los educadores sociales, me gustó y empecé Educación Social [...]. Cuando estaba haciendo la PSS, me impliqué mucho y la directora me dijo que, si estudiaba Educación Social, ella podría irme haciendo contratos de auxiliar educativo y, con eso, me iría pagando los estudios [...].

(D. A., educador, dos años en los servicios sociales de base).

$-N$. A.: Fui escolta [scout] de $1^{\circ}$ a $3^{0}$ de BUP, que es el momento en el que empecé a trabajar, pero antes ya había estado en Santo Cristo [un barrio popular de la ciudad de Badalona] e incluso en algún esplai de parroquia.

-Ego: ¿Los estudios sociales?

-N. A.: Yo estudié Educación Social, pero ya había empezado a trabajar en el Esplai Llevant con disminuidos psíquicos.

-Ego: ¿Cobrando?

-N. A.: ¡No, no! A partir de lo del Esplai Llevant, se hizo ESPANIN [Asociación de Disminuidos Psíquicos de Badalona], que es una entidad que ha montado muchos servicios para los disminuidos psíquicos de Badalona. [...] entonces ahí tuve un contrato de seis meses, se crearon los pisos para adultos y es entonces que entré contratada. Fue en ese momento que empecé los estudios de Pedagogía, y lo dejé al poco tiempo para estudiar Educación Social en Flor de Maig [...]."

(N. A. educadora social, catorce años en los servicios sociales de base).

-E.: Estamos hablando de hace casi 25 años. Yo por ese entonces trabajaba; de hecho, soy delineante, tengo un FP de primer y segundo grado. Entonces trabajaba en una tienda de maquinaria industrial, pero en mi tiempo libre me relacioné 
con una serie de gente, entre ellos, el director de un centro de menores con quien yo colaboraba de forma voluntaria, dando clases de refuerzo -en Girona-, acompañando a alguna salida. En eso que quedó vacante un puesto de educadora, y me lo propusieron y dije que sí. Fue un poco por casualidad: no tenía formación alguna y la fui haciendo de a poco, y así entré en la primera promoción de la Escuela de Educadores de Girona.

(E., 1961, educadora, doce años en los servicios sociales de base).

Estas socializaciones en el mundo de 'lo educativo' o 'lo social', ya sea en esplais o escuelas religiosas, están también presentes en el caso de escolarizaciones que llegan con mayor puntuación al acceso a la Universidad y, por tanto, no se encuentran con la fatalidad de tener que elegir carreras por defecto.

Un último elemento que nos interesa señalar, y que es común a todos los miembros de nuestro universo de estudio, es que movilizan la noción de realizar un trabajo con 'sentido'. Es decir, la elección profesional, más allá de las condiciones objetivas que la condicionan, tiene relación con un rechazo de las profesiones 'sin sentido'. Dicha concepción de la profesión puede tener distintas interpretaciones. Con algunos de los nacidos en los años sesenta, parece relacionarse con la socialización de estos jóvenes en un momento histórico -años setenta- de cuestionamiento de estilos de vida más tradicionales, que corresponden a los de sus padres, y en el que la noción de una profesión 'con sentido' pasa por ejercer profesiones poco convencionales:

-A. N.: Mi madre me decía: “¿Qué es eso? ¿Por qué no haces Magisterio? ¿Por qué no haces Administración y trabajas con tu tío, en el banco?”. Pues yo no quiero estar en un banco, yo quiero ser asistente social, porque yo era muy jipi.

(A. N., 1963, trabajadora social, 23 años en los servicios sociales de base).

Para otros, esta concepción de la profesión como 'algo más' que un medio para ganar dinero parece relacionarse, en el caso de los nacidos a partir de los años setenta, con una concepción de la formación en términos de 'crecimiento personal', en oposición a una visión únicamente instrumental de los estudios. En los individuos de esta generación -la que nace a finales del Franquismo o al inicio de la democracia-, que se caracterizan por la ausencia de socializaciones militantes en partidos o sindicatos, y por la socialización en esplais o instituciones parecidas, se produce un cierto distanciamiento del trabajo como un medio de acumulación de bienes materiales, para transformarlo en un medio para vivir enriqueciéndose personalmente. Ess distanciamiento parece relacionarse con un proceso de ascenso social-aunque limitado respecto a las profesiones prestigiosas- con respecto al medio familiar, tanto en lo que se refiere a las calificaciones como al tipo de trabajo realizado.
La noción de 'sentido' - ‘trabajo con sentido'- parece declinarse en dos dimensiones: un trabajo que movilice 'el intelecto' por encima del 'cuerpo'; y un trabajo que aporte cosas 'en el ámbito personal', en oposición a un trabajo que no tiene ninguna otra finalidad que su propia ejecución. En suma, un distanciamiento propio de individuos en procesos de ascenso social de clases populares, o procedentes de segmentos de clases medias, sin estudios superiores y con pocas probabilidades de acceso a profesiones dominantes en el espacio social-abogados, empresarios-:

-S. A.: [...] Pero bueno, a mí ya me gustaba el tema, me gustaba mucho ayudar a la gente, y siempre estoy pendiente de lo que le pasa a uno y otro. Pues eso, cuando estuve en el extranjero, pensé que igual esta carrera [se refiere a Trabajo Social] me gustaría, más por interés personal que por otra cosa, no tanto para trabajar, porque yo ya tenía mi trabajo [técnica de laboratorio] y ya estaba bien, pero para enriquecerme y aprender. Entonces miré cómo iba el tema y me inscribí [...].

(S. A., 1976, trabajadora social, dos años en los servicios sociales de base).

- S. F.: Y cuando llegó a mis manos toda la información de Educación Social, sí que vi que, como formación personal, tenía mucho interés. Como la nota de corte me daba un poco baja, tuve que ir a la Pere Tarrés, y combiné trabajo y estudios.

-Ego.: ¿Tu nota de corte era baja?

- S. F.: Bueno, pinché en la Selectividad, nervios y tal, y no me daba, así que fui a Pere Tarrés, y la verdad es que todo fue muy rodado, alguna asignatura que me costó un poco más, pero me gustó mucho, la gocé mucho [...]. Había compañeros que estaban muy preocupados por si encontrarían trabajo o no, si las condiciones serían buenas o malas; yo disfruté de los tres años, saqué las mejores notas de mi toda mi escolaridad [...].

(S. F., 1976, educador social, cuatro años en los servicios sociales de base).

En síntesis, podemos caracterizar las trayectorias de los individuos que componen nuestro universo de estudio por su procedencia de familias de origen popular que invierten en la educación de sus hijos/as como modo de ascenso de éstos. En segundo lugar, cabe destacar la adhesión de los/as hijos/as a esa idea de la escuela como vía de ascenso social, aunque la mayoría realicen escolaridades que podríamos calificar de 'medias-bajas' en cuanto a las calificaciones. En tercer lugar, casi todos ellos forman parte de las generaciones en las que se produce un acceso importante de los/as hijos/as de clases populares a la Universidad. Por otro lado, la socialización en instituciones de educación no formal, de educación popular o, en menor medida, políticas o sindicales, significa oportunidades de profesionalización -un 
horizonte posible - frente al fracaso de otras vías, o como oferta real de acceso al mercado de trabajo. Posibilidades objetivas de acceso a la Universidad y al mercado de trabajo calificado se mezclan con una valorización del hecho de realizar trabajos con 'sentido', en oposición a trabajos cuya finalidad sea sólo su ejecución. Además, todos ellos dan valor a la dimensión 'intelectual' del trabajo - a los instrumentos propios de la profesión-, en oposición a un trabajo 'manual' o en 'el que no se deba pensar'. Todos estos elementos parecen combinarse, especialmente en el caso de las trabajadoras sociales, con una dimensión de género, en la que la socialización de las mujeres parece materializarse en una voluntad -'un gusto'- por 'ocuparse de los otros'.

Estas trayectorias parecen estar en la base de una adhesión a un ideal del educador o el trabajador social como alguien que establece una relación de ayuda en la que lo importante es generar un proceso 'educativo', definido como lo opuesto a un trabajo administrativo o asistencial. Administrar o asistir no tiene mucho 'sentido', ya que no implica la movilización del 'intelecto' -de lo aprendido en la Universidad-, ni ese 'ayudar' a los otros que permite dar al trabajo un elemento distintivo -valor simbólico, a falta de valor material y social- del resto de profesiones propias de los espacios populares -identificadas como manuales y repetitivas- y dominantes -identificadas como profesiones basadas en la acumulación de dinero-:

-M. C.: Tramitar prestaciones, pa' eso no hace falta estudiar una carrera. Sólo hacemos eso: la gente viene aquí para que tramites ayudas, y cuando tienes un tema educativo que podrías trabajar, te das cuenta que no tienes ni tiempo, ni nada.

(M. C., 1967, trabajadora social, veinte años en los servicios sociales de base).

Esta identidad profesional permite a los componentes de nuestro universo de estudio 'convertirse' en profesionales adquiriendo unas herramientas -conocimientos- a las que atribuyen gran valor, justamente porque les permiten pasar al estadio de 'profesionales', es decir, les ofrece el derecho de entrada a un mercado de trabajo calificado, a la vez que a una profesión con 'sentido'.

Cabe pensar que esta necesidad de encontrar 'sentido' al trabajo realizado quede reforzada por el bajo prestigio social y la poca visibilidad de las que goza la profesión, las pocas posibilidades de promoción existentes, $y$, para una parte de nuestro universo de estudio, la inestabilidad laboral persistente. Así, de todas las entrevistadas, sólo una persona ha sido promovida una vez dentro de los servicios sociales municipales, pero esas promociones sólo llevan hacia tareas de gestión, de forma que esta persona ha vuelto a los servicios sociales de base, con el argumento de que no encontraba 'sentido' en la gestión. En esta misma línea, a la pregunta sobre cómo se ven en el futuro profesionalmente, la totalidad de nuestros entrevistados no se ven en otro sitio que donde están, no por falta de ganas de hacer otras cosas - muchos manifiestan interés por ocupar posiciones de planificación de proyectos educativos-, sino por la ausencia de posibilidades 0 de condiciones materiales adecuadas:

-Ego: ¿Hacia dónde te gustaría evolucionar profesionalmente?

-S. N.: No sé, tal vez me gustaría hacer otras cosas.

-Ego.: ¿Qué tipo de cosas?

-S. N.: A ver, a mí me gusta el trabajo con las familias, pero es un trabajo que quema mucho. Creo que necesitamos épocas de descanso de la atención directa, y creo que iría bien que los profesionales que hacemos atención directa pudieran tener un tiempo en la retaguardia, aunque fuera haciendo tareas de gestión, y bueno, otro tipo de tarea, no sé exactamente cuál. A mí me gustaría hacer cosas de mediación, pero lo que se está haciendo aquí son cosas de mediación comunitaria, que están bien, pero son contratos con la Diputación, con lo cual, la contratación es muy precaria, de manera que no lo voy a hacer.

-Ego.: ¿Tienes contrato fijo aquí?

-S. N.: Desde hace 21 años.

-Ego: 0 sea, que, por el momento, no hay proyectos profesionales.

-S. N.: ¿Sabes qué pasa? Que muchas veces no es tanto lo que tú quieras como lo que haya; y es que también ves cómo está la organización y las posibilidades que hay dentro de ésta.

-Ego: ¿Cuáles son éstas en la ciudad?

-S. N.: Pues la verdad es que no hay [risas] [...].

(S. N., 1960, psicóloga, 21 años en los servicios sociales de base).

\section{La tramitación del acceso al Programa Interdepartamental de la Renta Mínima de Inserción como forma de validación de la identidad profesional}

Los profesionales de los servicios sociales de base, debido a la posición de privilegio que la arquitectura del dispositivo les otorga en el proceso de tramitación de la demanda de acceso al Programa Interdepartamental de la Renta Mínima de Inserción (PIRMI), pueden apropiarse de dicho dispositivo y dotarlo de significado en función de su identidad profesional. De esta forma, la decisión de tramitar o suspen- 
der, aparte de a los obligados criterios objetivos marcados por la ley del PIRMI, estará vinculada a la probabilidad percibida por los trabajadores sociales de poder realizar un trabajo 'educativo'. De la misma forma, la percepción, por parte del profesional, de la imposibilidad de realizar un trabajo 'educativo' con el usuario retardará o limitará las posibilidades de tramitación o continuidad en el dispositivo:

-M. C.: [...] con él no he conseguido que haga nada.

-Ego.: ¿Pero les has mantenido el PIRMI?

-M. C.: A ver, les he hecho alguna 'suspensión terapéutica' que digo yo: un par de veces, en los períodos en los que él no hacía nada, había absentismo escolar, teníamos problemas con la escuela, porque el señor es agresivo, es muy de 'yo hago lo que quiero y tú no me digas nada'. Entonces, si el tema es que él hace lo que quiere, pues muy bien, yo le suspendo el PIRMI, pero sólo durante un período corto de tiempo, ya que con la señora sí que puedo hacer cosas [...].

(M. C., 1967, trabajadora social, dieciséis años en los servicios sociales de base).

-A.: [...] Hablo con la PIRMI y les dije: "yo no sé cuál es la situación”. Me entrevisto con él, me dice que su padre había estado en el hospital y que, por eso, había tenido que ir [a Marruecos]. "Pues tráeme un documento", "no lo tengo, porque allí [en Marruecos] no funciona de esa forma, tengo que pagar"; y dije: "pues mira, si no me traes el documento, se cortará la PIRMI”, y se le ha cortado la PIRMI hasta que no aporte el documento; y mira que la situación... Y es una lástima, porque mira que la familia podía tirar para'lante, porque cobraban 700 y pico de euros y podían tirar para'lante, pero claro, si esa gente coge y se van, claro, yo entonces, ¿qué soy?, ¡soy pura tramitadora!

(A., 1972, educadora social, nueve años en los servicios sociales de base).

Vemos en este extracto de entrevista que, a pesar que potencialmente la educadora social percibía posibilidades de trabajo ‘educativo', la ausencia prolongada del beneficiario del territorio y, por tanto, de los servicios sociales donde la educadora realiza la tarea 'educativa', hace que la profesional se perciba automáticamente como 'tramitadora', un rol que se sitúa a las antípodas de la identidad profesional que hemos descrito y que implica automáticamente la demanda de suspensión de la prestación por su parte. Cabe señalar el adjetivo usado por la educadora, "pura", que nos indica que las tareas administrativas, de trámite, son aceptadas siempre que sean el medio por el cual el trabajo educativo puede empezar, es decir, siempre que esas tareas no sean 'puras', sino 'mezcladas' con las educativas.
Esta fusión entre el derecho (la renta mínima de inserción) y la identidad profesional es tan fuerte que incluso la continuidad/suspensión del derecho puede ser percibida, por parte de los trabajadores sociales, como un instrumento educativo, más que como un derecho. Así, una educadora nos relata que, después de suspender la participación de una usuaria en el PIRMI, no piensa volver a activar la prestación hasta que no perciba los cambios que ella considera necesarios en el proceso 'educativo' emprendido con ella. Es más, cuenta con que la suspensión de la prestación sea una manera de 'hacer reaccionar' a la usuaria:

-T. T.: Tengo un caso, por ejemplo, de una familia que durante seis años ha estado cobrando el PIRMI y actualmente no le estoy activando la PIRMI/RMI [se la ha suspendido], o sea, una familia que durante seis años ha estado cobrando la PIRMI, en el momento en que no se cumplieron los acuerdos, se paró y sigo con el plan de trabajo; y ahora que no hay la PIRMI, deberían haber cambios [...] la mujer reconoce a la pareja, por lo tanto, no se quiere separar, que era uno de los elementos para volver a activar la PIRMI; pues si es así, ahora deberá organizarse con los recursos que existan a nivel de servicios sociales [fuera del PIRMI/RMI]: ayudas [económicas] puntuales, derivación a módulos de técnicas de búsqueda de empleo, recordar periodos de inscripción [de los niños a la escuela], soporte de comedor [beca de comedor] si es necesario, los recursos mínimos sin activar una PIRMI/RMI.

-Ego.: ¿Esto lo has decidido tú?

-T. T.: Sí.

-Ego.: ¿Por qué razón no quieres activar la PIRMI?

-T. T.: Porque durante seis años ha estado cobrando un dinero y su situación familiar no ha cambiado [...] se trata [de] que reconozca la situación en la que se encuentra [...]. Ella [la usuaria] no es consciente de la realidad [...], es una mujer muy pasiva en relación a sus circunstancias, se refugia en el regazo de su madre y así mantiene relaciones con su pareja como una pareja libre, como si fuese su novio, no como un hombre con sus responsabilidades, con sus valores, como un padre de familia, vaya, pum, pum, donde participa en según qué tareas, que acompañara a los niños de forma puntual, que pudieran presentarse como una familia unitaria y que quisieran luchar por una casa, entonces podríamos valorar la PIRMI [...].

(T. T., educadora social, dos años en los servicios sociales de base. [Subrayado del autor]).

Sólo en los casos en los que la situación de la familia es juzgada como muy límite por parte del profesional, se puede concebir no respetar la regla de tramitar o dar continuidad a la prestación, a pesar de que no se esté validando la identidad profesional. Es a menudo 
el caso de familias con hijos muy pequeños y sin ningún tipo de recurso económico:

-S. R.: A ver, tú das unos ingresos económicos, ¡saca estos ingresos! ¿Qué haces? ¿La quitas? ¡Se quedan sin nada! El sistema es un poco perverso: parten de la premisa que tú tienes clara, y la usuaria también, que esto es una contraprestación. Pero tú, con unidades familiares con cuatro hijos que deben cobrar 800 euros, ¿por incumplimiento retiras [el] PIRMI? ¿Qué harás ahora con esa familia, que ahora teóricamente, teóricamente, no tendrá ingresos?

(S. R., 1961, veinte años en los servicios sociales de base).

No obstante, en estos casos el PIRMI es percibido como un dispositivo disfuncional que debería ser modificado en su estructura, para que la identidad profesional pueda ser validada. Dicho en otros términos, cuando el PIRMI no sirve de instrumento de validación de la identidad profesional se considera que debe modificarse de forma que sirva justamente a este fin:

-S. R.: Yo haría que [la renta mínima de inserción] fuese una pensión universal y punto, sin contraprestación, así nosotros podemos dedicar esfuerzos para personas a quien[es] esto les es realmente necesario y no estaremos haciendo gestiones, buscando recursos, cursos, por todas partes, para personas que, al cabo de unos días, te vienen con un papel diciendo que tienen una hernia, ¿me explico? Entonces, es que un PIRMI da mucho trabajo, igual en otras partes será de otra manera, pero en los territorios donde yo he trabajado presentan muchas dificultades, tanto de gestión, búsqueda de recursos, como de perseguir a la gente, y entonces, perdemos mucho tiempo, en general. Aparte de esto, hay veces que has estado haciendo todo un trabajo y luego, cuando las cosas han avanzado, te dicen [se refiere a los órganos de gestión del PIRMI del Gobierno catalán]: "no hay cursos". Entonces, vamos a ver, si no hay salidas formativas para las personas, tú no puedes llenarte la boca metiendo presión al usuario, porque después te vienen con papeles del IMPO [Instituto Municipal de Promoción de la Ocupación ${ }^{6}$, Grameimpuls ${ }^{7}$, diciendo que no hay cursos.

(S. R., 1961, veinte años de servicio en los servicios sociales de base).
Finalmente, como habíamos empezado a indicar, la noción de trabajo 'educativo' no es uniforme entre los distintos profesionales. Para algunos, el trabajo 'educativo’ en el seno del PIRMI es entendido esencialmente como un trabajo que lleve a la participación del usuario o usuaria en dispositivos de formación que permitan llegar a encontrar un empleo o tener una mínima formación académica. Sin embargo, para otros esta noción puede ser mucha más amplia:

-S. N.: Mira, yo creo que un PIRMI, en este caso, senso strictu con la filosofía del PIRMI, no tendría que ser, ¿vale?

-Ego.: ¿Porque no habrá inserción?

-S. N.: Claro, yo me planteaba que ella tuviera una PIRMI, y él, una PNC [pensión no contributiva], pero claro, yo dudo que esta señora pueda tener una inserción, porque además la familia tampoco le va a dejar y... Pero supongo que, al menos, podremos romper un poco el nivel de poder. Nosotros no podemos romper el nivel de poder en la pareja, pero si el equilibrio, con pequeños empujones; lo podemos modificar un poco para que la señora tenga una vida más... Y es que cada vez está peor físicamente, cada vez más triste, y además cada vez tiene más problemas con el señor... Bueno y es que ¡está cansada! Está cansada y no la tratan bien [...].

(S. N., 1960, trabadora social, veinte años en los servicios sociales de base).

-V. R.: Un segundo perfil sería la gente que ha tenido una trayectoria -ahora me estoy acordando- que serían laborales con una trayectoria bohemia. Nosotros aquí, en el barrio, que es un barrio obrero, hay muchas casas antiguas y tal, y hay mucha ocupación, hay muchos okupas, ¿no? Aquí hay varias casas, aquí, en la montañita que se ve, varias casas tapiadas, hay okupas, ¿vale? Un día llegó aquí una pareja punki, panki, ¡dígale como sea! [...] pues vivían de vender en mercadillos y tal [tono de descalificación], venta ambulante sin cotizar, [ya] sabes, aquello [de]: "yo estoy en contra del sistema totalmente", [tono descalificante], "a mí todo lo que tenga que ver con el trabajo, todo esto de cotizar, ¡no!”; iba contra su ideología [tono descalificante]. Entonces, ¿qué pasa? 0 sea, por un lado, quiero estar fuera del sistema, y por el otro, tengo derecho y jno tengo obligación! Entonces esta familia cumplen los requisitos y, en un momento determinado, ella se ha quedado embarazada, se les tramita [la prestación], pero para que ellos puedan hacer otro replanteamiento de vida, ¿no?

(V. R., 1980, trabajadora social, cuatro años en los servicios sociales de base).

En el primer caso, vemos que el trabajo 'educativo' tiene mucho que ver con una transformación de la situación matrimonial de una mujer a partir de la

\footnotetext{
${ }^{6}$ El Instituto Municipal de Promoción de la Ocupación (IMPO) es un organismo autónomo municipal que tiene como objetivo mejorar la ocupabilidad de la población del municipio. Para ello, esta entidad oferta cursos y recursos para las personas que buscan trabajo.

7 Grameimpuls es una empresa municipal que busca promover la ocupación y la actividad empresarial. En este sentido, oferta cursos de formación ocupacional a los que son enviados las personas sin trabajo del municipio o de la comarca.
} 
movilización de instrumentos de la psicología -las relaciones de poder en el seno de una pareja-. En este último caso, las competencias profesionales particulares de la profesional determinan el contenido y sentido dado al acceso al PIRMI. En el segundo caso, el trabajo ‘educativo’ y la decisión de tramitación van unidos, por el contrario, a un cambio de estilo de vida vinculado a posiciones ideológicas de la profesional. Así, ésta defiende un modelo de estar en sociedad -tener un trabajo estable, cotizar a la Seguridad Social- que quiere que sus usuarios compartan.

\section{Conclusión}

A lo largo de este trabajo, hemos visto que la magistratura concedida a los profesionales de lo social en el acceso a un derecho social -la renta mínima de inserción- se confunde con una identidad profesional. Esta identidad profesional está socialmente situada. Es decir, la manera de concebir la tarea en los servicios sociales de base está vinculada a ciertas trayectorias sociales que corresponden a la interrelación entre biografías individuales y contextos sociopolíticos en España. Además, esta identidad profesional -hacer un trabajo 'educativo'-, si bien coincide, en términos generales, entre profesionales, presenta múltiples variantes en lo que concierne a sus concreciones. Para algunos, este trabajo educativo pasa por una inserción profesional esencialmente; para otros, por intervenir en dinámicas relacionales a partir del uso de conocimientos en el campo de la psicología; y, finalmente, para otros pasa por conseguir un cambio de posicionamiento ideológico del beneficiario.

En este sentido, podemos decir que la magistratura social que las rentas mínimas conllevan, al menos en el caso catalán, vincula derechos sociales a variables socialmente situadas, sometidas a transformaciones potenciales. Se puede, por ello, establecer que la magistratura de lo social implica que el sentido y contenido de los derechos sociales quede muy vinculado a la posición social de los magistrados, que se tornan productores de derecho en relaciones localizadas e interpersonales. 
AGUILAR, M. et al. (1995): La caña y el pez. El salario social en las comunidades autónomas, 1989-1994, Madrid, Fundación FOESSA.

ARRIBA, A. (1999): Rentas mínimas de inserción en España: procesos de implantación y dinámicas sociales [tesis doctoral], Madrid, Universidad Autónoma de Madrid.

BOURDIEU, P. (1979): La distinction. Critique sociale du jugement, París, Éditions de Minuit.

CASTEL, R. (1995): Les métamorphoses de la question sociale, París, Fayard.

CORTINAS, J. (2010): La renta mínima de inserción y la lucha contra la pobreza en Cataluña. Sociología de una reforma de los modelos de protección social [tesis doctoral], Barcelona, Universidad Autónoma de Barcelona; París, École des Hautes Études en Sciences Sociales.

DUBOIS, V. (2003a): “La sociologie de l’action publique. De la socio-histoire à l'observation des pratiques (et vice-versa)", en LABORIER, P.; y TROM, D., Historicités de l'action Publique, París, PUF, págs. 347-364 [<http://halshs. archives-ouvertes.fr/docs/00/46/43/22/PDF/ sociologiedelalactionpbliq.pdf $>$.

- (2003b): La vie au guichet. Relation administrative et traitement de la misère, París, Economica.

PRESIDÈNCIA DE LA GENERALITAT (2001a): “Decret 118/2001, de 2 de maig, pel qual es modifica el Decret 306/1998, d'1 de desembre, de desplegament de la Llei 10/1997, de 3 de juliol, de la Renda Mínima d'Inserció", Oficial de la Generalitat de Catalunya, nํㅜ 3.390, 17-5-2001, págs. 7.169 [khttp://tinyurl.com/7v5f6uos]. (2001b): “Decret 316/2001, de 20 de novembre, pel qual es modifica el Decret 306/1998, d'1 de desembre, de desplegament de la Llei 10/1997, de 3 de juliol, de la Renda Mínima d'Inserció”, Diari Oficial de la Generalitat de Catalunya, n- 3.531, 11-12-2001, pág. 18.994 [<http:// tinyurl.com/7bgb6xa〉].

- (1998): “Decret 306/1998, d'1 de desembre, de desplegament de la Llei 10/1997, de 3 de juliol, de la Renda Mínima d'Inserció", Diari Oficial de la Generalitat de Catalunya, n- 2.787, 1112-1998, págs. 15.286-15.290 [<http://tinyurl. com/7r2fh9g'].

- (1997): “Llei 10/1997, de 3 de juliol, de la Renda Mínima d'Inserció", Diari Oficial de la Generalitat de Catalunya, no 2.435, 17-7-1997, págs. 8.1828.187 [khttp://tinyurl.com/78hzdbc)].

- (1990): “Decret 144/1990, de 28 de maig, regulador del Programa Interdepartamental de la Renda Mínima d'Inserció (PIRMI)", Diari Oficial de la Generalitat de Catalunya, $\mathrm{n}-1.309,25-$ 6-1990, págs. 2.891-2.894 [khttp://tinyurl. com/85zo4gb〉].

LIPSKY, M. (1980): Street-level Bureaucracy. Dilemmas of the Individual in Public Services, Nueva York, Russell Sage Foundation.

SERRE, D. (2009): Les coulisses de l'État Social. Enquête sur les signalements d'enfant en danger, París, Raisons d'Agir.

SPIRE, A. (2008): Accueillir ou reconduire. Enquête sur les guichets de l'immigration, París, Raisons d'Agir.

TISSOT, S. (2007): L'État et les quartiers. Genèse d'une catégorie de l'action publique, París, Seuil. 